\title{
Breast fibroadenomas are not associated with increased breast cancer risk in an African American contemporary cohort of women with benign breast disease
}

Asra N. Shaik', Julie J. Ruterbusch', Eman Abdulfatah², Resha Shrestha ${ }^{2}$, M. H. D. Fayez Daaboul ${ }^{2}, V^{1}$ sakha Pardeshi², Daniel W. Visscher ${ }^{3}$, Sudeshna Bandyopadhyay ${ }^{4}$, Rouba Ali-Fehmi ${ }^{2,4}$ and Michele L. Cote ${ }^{1,4^{*}}$ [D

\begin{abstract}
Background: Fibroadenomas are common benign breast lesions, and studies of European American women indicate a persistent, increased risk of breast cancer after diagnosing a fibroadenoma on biopsy. This association has not been independently assessed in African American women, despite reports that these women are more likely to present with fibroadenomas.

Methods: The study cohort included 3853 African American women with a breast biopsy completed between 1997 and 2010 in metropolitan Detroit. Biopsies were microscopically reviewed for benign breast lesions, including fibroadenoma, proliferative disease, and atypia. Risk of breast cancer within the cohort was estimated using relative risk ratios and $95 \%$ Cls calculated using multivariable log-binomial regression. Relative risk of breast cancer in this cohort compared with African American women in the broader metropolitan Detroit population was estimated using standardized incidence ratios (SIRs).

Results: Fibroadenomas occurred more frequently in biopsies of younger women, and other types of benign breast lesions were less likely to occur when a fibroadenoma was present $(p=0.008$ for lobular hyperplasia; all other $p$ values $<0.01)$. Unlike women with other benign lesions ( $\mathrm{SIR}, 1.41 ; 95 \% \mathrm{Cl}, 1.20,1.66)$, women with fibroadenomas did not have an increased risk of developing breast cancer compared with the general population $(\mathrm{SIR}, 0.94 ; 95 \% \mathrm{Cl}$, $0.75,1.18)$. Biopsies that indicated a fibroadenoma were associated with a reduced risk of breast cancer after adjusting for age at biopsy, proliferation, and atypia (relative risk, $0.67 ; 95 \% \mathrm{Cl}, 0.48,0.93$ ) compared with biopsies without a fibroadenoma.
\end{abstract}

Conclusions: These findings have important implications for breast cancer risk models and clinical assessment, particularly among African American women, in whom fibroadenomas are common.

Keywords: Benign breast disease, Breast cancer, Risk, African American

\footnotetext{
* Correspondence: cotem@karmanos.org

${ }^{1}$ Department of Oncology, Wayne State University School of Medicine, 4100

John R Street, MM04EP, Detroit, MI 48201, USA

${ }^{4}$ Barbara Ann Karmanos Cancer Institute, Detroit, MI, USA

Full list of author information is available at the end of the article
}

(c) The Author(s). 2018 Open Access This article is distributed under the terms of the Creative Commons Attribution 4.0 International License (http://creativecommons.org/licenses/by/4.0/), which permits unrestricted use, distribution, and reproduction in any medium, provided you give appropriate credit to the original author(s) and the source, provide a link to the Creative Commons license, and indicate if changes were made. The Creative Commons Public Domain Dedication waiver (http://creativecommons.org/publicdomain/zero/1.0/) applies to the data made available in this article, unless otherwise stated. 


\section{Background}

Over 1.5 million breast biopsies are pathologically assessed annually in the United States, indicated by abnormal mammography findings or patient complaints [1]. Most biopsies are not malignant, but instead exhibit a number of pathological lesions that constitute benign breast disease (BBD). Biopsies that exhibit proliferative disease or cellular atypia, as defined by Dupont and Page criteria, are consistently associated with increases in breast cancer risk [2-4]. These pathologic criteria have been included in risk assessment models to identify women at high risk of developing breast cancer. Several current risk assessment models, including the frequently used Breast Cancer Risk Assessment Tool, incorporate information on the number of prior biopsies and the presence of atypia on biopsy, but they do not account for other BBD lesions that may independently increase breast cancer risk [5]. Reliable estimates of breast cancer risk associated with individual lesions can improve risk models, allowing physicians to better identify women at high risk of developing breast cancer who may benefit from additional screening or chemoprevention.

One type of BBD, fibroadenomas, are well-circumscribed benign tumors of epithelial and stromal tissue (Fig. 1) [6]. Breast fibroadenomas most frequently occur in women in their 20s [6] but can occur at any age; it is estimated that $10 \%$ of women have breast fibroadenomas [7]. A recent meta-analysis of 11 studies reported an increase in breast cancer risk by $41 \%(1.41$; $95 \%$ CI, $1.11-1.80)$ for women diagnosed with a fibroadenoma compared with women without fibroadenoma on biopsy; however, significant statistical heterogeneity was also reported with this estimate [8]. Furthermore, the studies in this meta-analysis were primarily in European ancestral populations, and the majority were

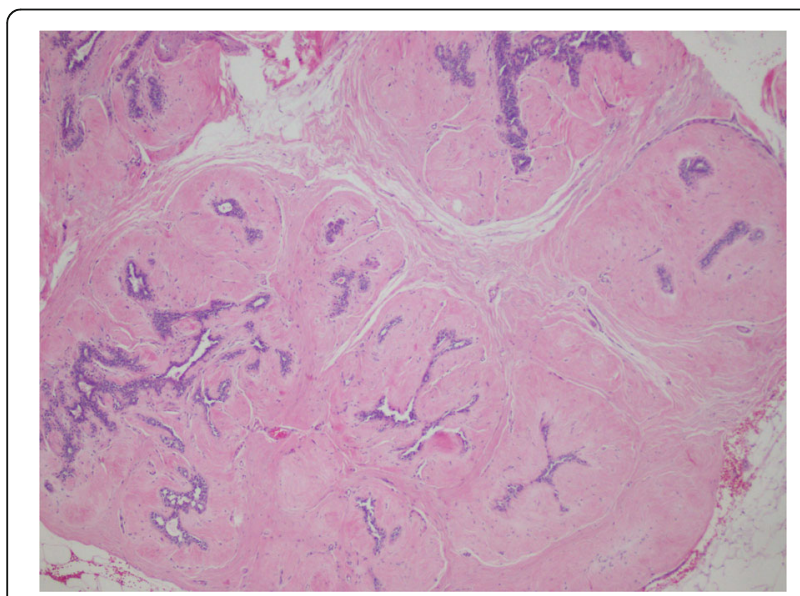

Fig. 1 Fibroadenoma. Fibroadenomas are benign tumors of stromal and epithelial tissue that are typically well-circumscribed and mobile within the tissue. The fibroadenoma shown here exhibits purple epithelial tissue surrounded by pink fibrotic stromal tissue (H\&E stain; original magnification $100 \times$ ) studies done prior to the widespread use of screening mammography in the 1980s. Although African American women experience a higher incidence and recurrence of fibroadenomas at a younger age $[9,10]$, breast cancer risk associated with this lesion has not been independently assessed in this population of women.

African American women have a $42 \%$ higher breast cancer mortality rate than European American women [11], a burden that stems partly from differences in tumor biology. African American women are more likely to develop breast cancer at a younger age [12-14] and more likely to be diagnosed with aggressive tumors characterized by high molecular grade $[15,16]$ and lack of hormone receptors $[13,15,16]$. Despite this survival disparity, prior investigations on BBD and breast cancer risk focused on mostly European American cohorts. The goal of this study is to examine in a contemporary cohort whether breast cancer risk associated with fibroadenoma differs for African American women, a population more likely to present with fibroadenomas and more likely to develop aggressive breast cancers that respond poorly to treatment.

\section{Methods \\ Study population}

African American women with their first benign breast biopsies conducted between 1997 and 2010 were identified using University Pathology Group (UPG; Detroit, MI, USA) records. UPG provides pathology services to several hospitals in metropolitan Detroit. Women aged 18 to 84 years at the time of benign breast biopsy were eligible for this institutional review board-approved study. Exclusionary criteria included a diagnosis of invasive or in situ breast carcinoma before or within 6 months of the breast biopsy, a history of mastectomy or reduction mammoplasty, lipoma, fat necrosis, epidermal cysts, hematoma, accessory structure, phyllodes tumor, or a lymph node biopsy without breast tissue. For this type of study, the Wayne State University Institutional Review Board determined that formal consent was not required.

\section{Histological review}

Core needle and excisional benign biopsies were microscopically reviewed by blinded study pathologists (RAF, $\mathrm{SB})$ using original H\&E-stained slides. Slides from the first biopsy were assessed for the presence of 12 pathologic lesions, including apocrine metaplasia, calcifications, columnar alterations, cysts, duct ectasia, ductal hyperplasia, fibroadenoma, fibrosis, intraductal papilloma, lobular hyperplasia, radial scars, and sclerosing adenosis. The biopsies were additionally categorized into three groups using criteria described by Dupont and Page [2] based on the presence of proliferative disease and cellular atypia. Biopsies classified as showing atypia and a random sample 
of all other biopsies were reassessed by a blinded study pathologist at the Mayo Clinic (DWV). Breast biopsies that could not be assessed for fibroadenoma presence were excluded from analysis $(n=23)$.

\section{Cancer ascertainment}

Women who developed breast cancer were identified through hospital medical records and also through the use of the Metropolitan Detroit Cancer Surveillance System (MDCSS), a founding member of the National Cancer Institute's Surveillance, Epidemiology, and End Results (SEER) program. MDCSS collects cancer incidence, treatment, and survival data in the tricounty metropolitan Detroit area. Use of both data sources allowed the identification of cancers in women residing in the entire tricounty metropolitan Detroit area. Women were matched between UPG records and MDCSS using name, date of birth, and/or Social Security number; follow-up information was complete to December 31, 2015. Median length of follow-up was 13.3 years (range, $0.5-19.0$ years); median time to breast cancer diagnosis was 6.6 years (range, $0.7-18.5$ years).

\section{Statistical analysis}

Associations between fibroadenoma and other benign lesions were examined using chi-squared tests. Relative risks of breast cancer associated with biopsies, with or without fibroadenoma, were estimated using age-adjusted standardized incidence ratios (SIRs) calculated from SEER estimates of cancer incidence in African American women in MDCSS from 1999 to 2014. Risk of breast cancer associated with fibroadenomas relative to other nonfibroadenoma BBD was examined within the cohort by relative risk ratios and 95\% CIs calculated using multivariable log-binomial regression and adjusting for age at biopsy. Regression models were further adjusted using backwards selection based on Bayesian information criteria. Models were stratified by age (below or above 50 years) to estimate risk based on likely menopausal status. Time to breast cancer diagnosis was assessed using competing risk analysis with death considered as a competing risk.

\section{Results}

\section{Distribution of BBD features and characteristics by fibroadenoma status}

A total of 3845 benign breast biopsies were assessed in this African American cohort, 1798 (47\%) of which were diagnosed with fibroadenoma. Fibroadenomas showed high concordance between pathologists (86.9\%; Cohen's $\kappa=0.7022$ ). Women with a fibroadenoma on biopsy were more likely to be under the age of 40 years at biopsy (31.9\%) than women without a fibroadenoma on biopsy $(18.9 \%)(p<0.001)$ (Table 1). The presence of a fibroadenoma was associated with the absence of all other benign breast lesions assessed on biopsy ( $p=0.008$ for lobular hyperplasia; all other $p<0.001$ ) (Table 1 and Additional file 1: Tables S1 and S2). Additionally, biopsies with a fibroadenoma were less likely to be classified as proliferative disease $(25.0 \%)$ or proliferative disease with atypia $(1.3 \%)$ than biopsies without a fibroadenoma (51.5\% and $6.1 \%$, respectively).

\section{Breast cancer risk compared with population level risk} Overall, this cohort of women exhibited an increased incidence of approximately 20\% (SIR, 1.19; 95\% CI, 1.05-1.36) of breast cancer compared with the general African American population in metropolitan Detroit (Table 2). Stratifying the cohort by presence of fibroadenoma on biopsy revealed that breast cancer incidence associated with fibroadenoma was indistinguishable from population level (SIR, 0.93; 95\% CI, 0.75-1.17), but the breast cancer incidence associated with the absence of fibroadenoma on biopsy was significantly higher than population level (SIR, 1.40; 95\% CI, 1.19-1.65).

\section{Breast cancer risk within the BBD cohort}

Adjusting for age at biopsy alone, the presence of fibroadenoma was associated with a reduced breast cancer risk (relative risk [RR], 0.64; 95\% CI, 0.45-0.85) compared with the absence of fibroadenoma within the BBD cohort (Table 3). When the model was fully adjusted for age at biopsy, proliferation, and atypia, fibroadenoma was still associated with a reduced risk (RR, 0.67; 95\% CI, 0.48-0.93) of developing breast cancer. Fibroadenoma diagnosed in women under the age of 50 years was associated with a decrease in breast cancer risk after adjusting for age at biopsy, proliferation, and cellular atypia (RR, 0.58; 95\% CI, $0.34-0.96$ ). Fibroadenoma diagnosed in women aged 50 years or older also showed a reduction in breast cancer risk but failed to reach statistical significance after adjusting for age at biopsy, proliferation, and cellular atypia (RR, 0.79; 95\% CI, 0.52-1.19).

\section{Cumulative incidence of cancers in subgroups}

Women with fibroadenoma on biopsy accumulated fewer breast cancers over the study period than women without fibroadenoma on biopsy (Fig. 2) $(p<0.001$ by Fine and Gray test). Stratifying by likely menopausal status by age indicated the incidence of breast cancers was lower in women under the age of 50 years than in women aged 50 years or older (data not shown). In both strata, women with fibroadenoma on biopsy accumulated fewer cancers over the study period than women without fibroadenoma on biopsy (Fine and Gray test, $p=0.014$ for under age 50 years and $p=0.059$ for ages 50 years and older). 
Table 1 Distribution of benign breast features and other characteristics by fibroadenoma status

\begin{tabular}{|c|c|c|c|}
\hline \multirow[t]{2}{*}{ Characteristic } & \multicolumn{2}{|l|}{ Status, $n(\%)^{\mathrm{a}}$} & \multirow[t]{2}{*}{$P$ value } \\
\hline & $\begin{array}{l}\text { No fibroadenoma } \\
2047 \text { (53.2) }\end{array}$ & $\begin{array}{l}\text { Fibroadenoma } \\
1798 \text { (46.8) }\end{array}$ & \\
\hline Age at benign biopsy, years & & & $<0.001$ \\
\hline$<40$ & $387(18.9)$ & $573(31.9)$ & \\
\hline $40-49$ & $692(33.8)$ & $582(32.4)$ & \\
\hline $50-59$ & $577(28.2)$ & $374(20.8)$ & \\
\hline $60-69$ & $249(12.2)$ & $164(9.1)$ & \\
\hline $70+$ & $142(6.9)$ & $105(5.8)$ & \\
\hline Biopsy type & & & $<0.001$ \\
\hline Excisional & $826(40.4)$ & $536(30.8)$ & \\
\hline Core needle & $1221(59.6)$ & $1262(70.2)$ & \\
\hline Apocrine metaplasia & & & $<0.001$ \\
\hline Absent & $1202(58.7)$ & $1401(82.3)$ & \\
\hline Present & $845(41.3)$ & $301(17.7)$ & \\
\hline Ductal hyperplasia & & & $<0.001$ \\
\hline Absent & $1272(62.1)$ & $1365(80.6)$ & \\
\hline Present & $775(37.9)$ & $329(19.4)$ & \\
\hline Lobular hyperplasia & & & 0.008 \\
\hline Absent & $2012(98.3)$ & $1662(99.3)$ & \\
\hline Present & $34(1.7)$ & $11(0.7)$ & \\
\hline Calcifications & & & $<0.001$ \\
\hline Absent & $1209(59.1)$ & $1229(70.8)$ & \\
\hline Present & $837(40.9)$ & $507(29.2)$ & \\
\hline Cysts & & & $<0.001$ \\
\hline Absent & $970(47.4)$ & $1339(78.9)$ & \\
\hline Present & $1076(52.6)$ & $359(21.1)$ & \\
\hline Duct ectasia & & & $<0.001$ \\
\hline Absent & $1652(80.7)$ & $1546(91.0)$ & \\
\hline Present & $394(19.3)$ & $152(9.0)$ & \\
\hline Fibrosis & & & $<0.001$ \\
\hline Absent & $648(31.7)$ & $1031(63.8)$ & \\
\hline Present & $1397(68.3)$ & $586(36.2)$ & \\
\hline Intraductal papilloma & & & $<0.001$ \\
\hline Absent & $1662(81.2)$ & $1629(96.1)$ & \\
\hline Present & $385(18.8)$ & $66(3.9)$ & \\
\hline Sclerosing adenosis & & & $<0.001$ \\
\hline Absent & $1416(69.2)$ & $1404(82.7)$ & \\
\hline Present & $630(30.8)$ & $294(17.3)$ & \\
\hline Columnar alterations & & & $<0.001$ \\
\hline Absent & 1302 (63.6) & $1439(84.7)$ & \\
\hline Present & $744(30.8)$ & $259(15.3)$ & \\
\hline Radial scar & & & $<0.001$ \\
\hline Absent & $1975(96.5)$ & 1665 (98.6) & \\
\hline Present & $71(3.5)$ & $23(1.4)$ & \\
\hline
\end{tabular}


Table 1 Distribution of benign breast features and other characteristics by fibroadenoma status (Continued)

\begin{tabular}{lll}
\hline Characteristic & $\begin{array}{l}\text { Status, } n(\%)^{\mathrm{a}} \\
\text { No fibroadenoma } \\
2047(53.2)\end{array}$ & $\begin{array}{l}\text { Fibroadenoma } \\
1798(46.8)\end{array}$ \\
\hline Dupont and Page criteria & & $1325(73.7)$ \\
$\quad$ Nonproliferative disease & $868(42.4)$ & $450(25.0)$ \\
Proliferative disease without atypia & $1054(51.5)$ & $23(1.3)$ \\
Proliferative disease with atypia & $125(6.1)$ & $1722(95.8)$ \\
Developed breast cancer & $1902(92.9)$ & $76(4.2)$ \\
No & $145(7.1)$ & 0.001 \\
Yes & &
\end{tabular}

${ }^{a}$ Numbers may not sum to the total number of patients if features could not be assessed on biopsy

${ }^{b} X^{2}$ test comparing distribution of features across absence or presence of fibroadenoma on biopsy

\section{Discussion}

We report findings in a contemporary cohort of African American women who have had a breast biopsy that show those with a fibroadenoma observed on biopsy are not at increased risk of subsequent breast cancer compared with the general population of African American women. When compared with all benign biopsies, biopsies that indicated a fibroadenoma were associated with a reduced risk of breast cancer that remains significant even after adjusting for age, proliferative disease, and atypia. These findings suggest that current breast cancer risk models that incorporate benign biopsies without considering the pathological lesion overestimate risk in African American women who have fibroadenomas on biopsy. Given that fibroadenomas were identified in nearly half of all breast biopsies in this population and were the only lesion identified in 19\% of all biopsies, these findings represent a significant clinical population.

Our investigation suggests that biopsies indicating fibroadenoma exhibit a reduced risk of breast cancer compared with all other BBD biopsies, contrary to most other studies' estimates of increased risk of breast cancer [8]. Discordant risk estimates between our investigation and those from other studies may reflect differences in race, age, and period of cohorts used. The Nashville group [17], which found a significant increase in breast cancer risk with fibroadenoma (SIR, 1.61; 95\% CI, 1.30-2.00) compared with the Connecticut Tumor Registry, studied European American women diagnosed with a fibroadenoma between 1950 and 1968. The Mayo Clinic BBD cohort [18] studied European American women diagnosed with fibroadenoma between 1967 and 1991 and found modest increases breast cancer risk with fibroadenoma (SIR, 1.60; 95\% CI, 1.38-1.85) compared with biopsies without fibroadenoma (SIR, 1.50; 95\% CI, 1.39-1.62). A BBD cohort from Henry Ford Health System (HFHS) [19], where women with fibroadenomas on biopsy had a decreased odds (OR, 0.55; 95\% CI, 0.39-0.77) of developing breast cancer compared with women without fibroadenoma on biopsy, more closely approximating our risk estimates, studied a mixed cohort of European American and African American women in metropolitan Detroit diagnosed between 1981 and 1994. However, it is unlikely that the differences in risk estimates are due solely to race: the HFHS group tested an interaction factor between race and BBD and did not find statistical significance [19].

Period effects may also contribute to variation in risk estimates. Inclusion criteria for BBD studies span from 1950 to 2010; thus, differences in risk estimates may also reflect the endogenous and exogenous exposures that varied over this period. Exogenous hormone use, including hormone replacement therapy and contraceptive use, have changed in frequency, dose, and formulation. Changes in exogenous hormone use can alter total estrogen exposure, a strong breast cancer risk factor, and influence risk estimates of tissue-based markers. Environmental exposures that vary over time and/or

Table 2 Risk of breast cancer compared with population level risk

\begin{tabular}{lll}
\hline & Standardized incidence ratio ${ }^{\text {a }}$ & 95\% confidence interval \\
\hline Population rate & Ref & $1.05-1.36$ \\
Entire BBD cohort $(N=221$ cancers) & 1.19 & $1.19-1.65$ \\
Biopsy without fibroadenoma $(N=145$ cancers) & 1.40 & $0.75-1.17$ \\
Fibroadenoma ( $N=76$ cancers) & 0.93 & \\
\hline
\end{tabular}

${ }^{a}$ Standardized incidence ratio compares the observed number of breast cancers that developed in the study to the number expected on the basis of the Detroit surveillance, epidemiology, and end results data for African American women of a similar age and calendar period 
Table 3 Relative risk of breast cancer by fibroadenoma status

\begin{tabular}{|c|c|c|c|c|}
\hline & Age-adjusted relative risk ${ }^{\mathrm{a}}(95 \% \mathrm{Cl})$ & $P$ value $^{\mathrm{b}}$ & Fully adjusted relative risk $(95 \% \mathrm{Cl})$ & $P$ value $^{\mathrm{b}}$ \\
\hline No fibroadenoma on biopsy & Ref & & Ref & \\
\hline Fibroadenoma & $0.64(0.48,0.85)^{d}$ & 0.003 & $0.67(0.48,0.93)^{\mathrm{e}}$ & 0.017 \\
\hline \multicolumn{5}{|l|}{ Under age 50 years } \\
\hline No fibroadenoma on biopsy & Reference & & Reference & \\
\hline Fibroadenoma & $0.71(0.45,1.11)^{f}$ & 0.133 & $0.58(0.34,0.96)^{9}$ & 0.037 \\
\hline \multicolumn{5}{|l|}{ Age 50 years or older } \\
\hline No fibroadenoma on biopsy & Reference & & Reference & \\
\hline Fibroadenoma & $0.68(0.46,0.98)^{\mathrm{h}}$ & 0.042 & $0.79(0.52,1.19)^{\mathrm{i}}$ & 0.275 \\
\hline
\end{tabular}

${ }^{a}$ Multivariable logistic regression model adjusting for age at biopsy

${ }^{b}$ Wald test statistic

${ }^{c}$ Multivariable logistic regression model adjusting for age, proliferative disease, and cellular atypia at biopsy

Number at risk: ${ }^{\mathrm{d}} 3845,{ }^{\mathrm{e}} 3761,{ }^{\mathrm{f}} 2234,{ }^{\mathrm{g}} 2071,{ }^{\mathrm{h}} 1611,{ }^{\mathrm{i}} 1536$

geographic areas can further add to risk estimate variation. Changes in the indication for biopsy are perhaps the most pertinent shift over these study periods: physicians are more likely to biopsy now than in the 1950s. Population uptake of mammography began in the 1970s [20], and screening technology has continued to improve since then $[21,22]$, leading to an increase in breast biopsy incidence. The adoption of core needle biopsies, which are less invasive than excisional biopsies, further increased the likelihood of a breast biopsy, especially in what are considered high-risk populations.

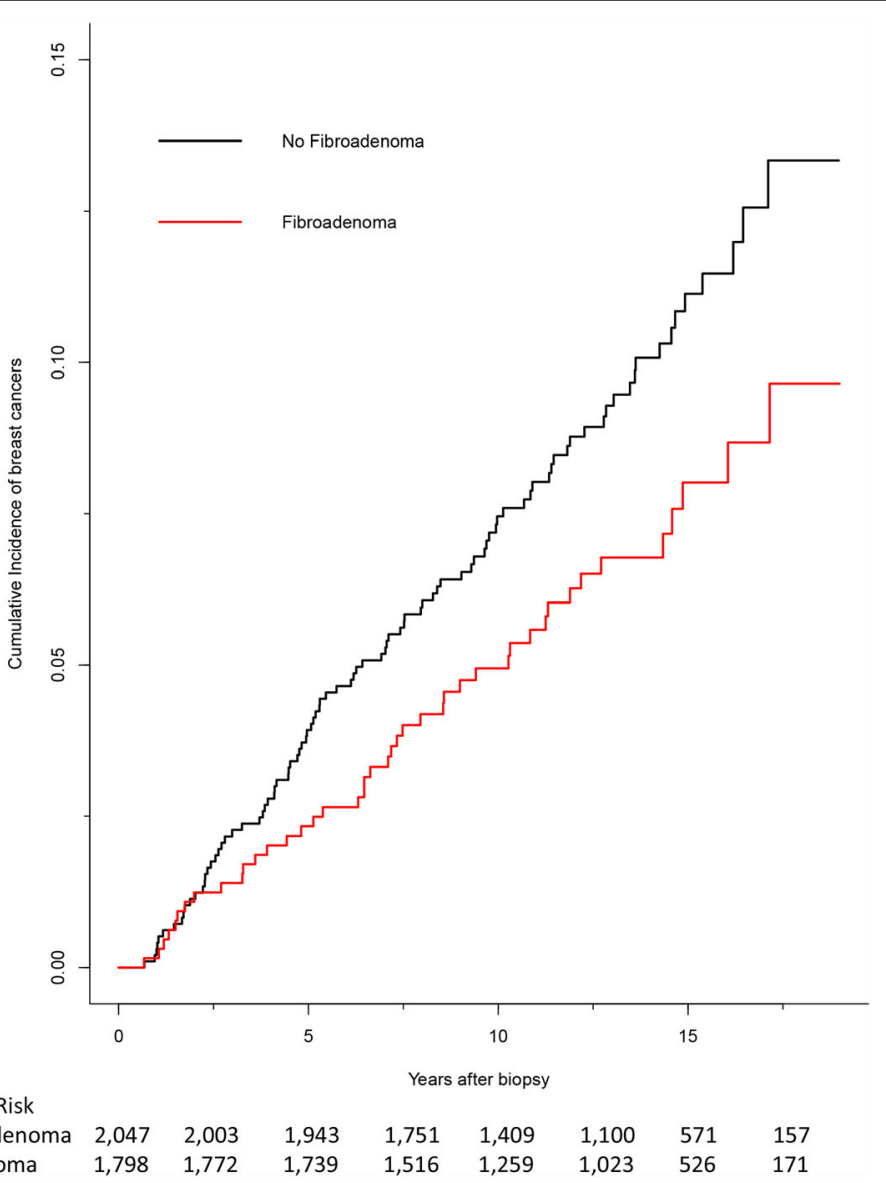

Fig. 2 Cumulative incidence of breast cancers over study period. Women with biopsies that indicated fibroadenomas accumulated fewer breast cancers over the study period than women whose biopsies did not indicate fibroadenomas. $p<0.001$ by Fine and Gray test 
The strengths of our study stem from the cohort study design, where all breast biopsies were reexamined for benign lesions in a centralized and standardized manner by Wayne State University pathologists, and identification of breast cancers occurred through institutional medical records and then standardized for the region through use of the population-based SEER registry. This allowed for the identification of breast cancers among women who sought care outside of the hospitals served by the UPG. It should be noted there are limitations to our study. First, the population estimates used in the SIR analysis includes women who have been diagnosed with BBD in the metropolitan Detroit area; thus, the SIR may slightly underestimate the risk associated with breast cancer. Next, our assessment was limited to the presence or absence of fibroadenomas on breast biopsy, but there may be added value in assessing whether these fibroadenomas exhibit other BBD lesions. There are conflicting reports on the breast cancer risk associated with complex fibroadenomas (fibroadenomas that exhibit cysts, calcifications, sclerosing adenosis, and/or apocrine metaplasia) [17, 18]. Because of the high prevalence of fibroadenomas in this population, breast cancer risk associated with complex fibroadenoma should also be independently reviewed in African American women.

\section{Conclusions}

Currently, a diagnosis of fibroadenoma requires no further intervention and is followed by a primary care physician or gynecologist unless the patient elects to have a mass removed, usually due to size of the tumor, recurrence, or pain $[23,24]$. Because previous investigations of fibroadenoma on biopsy estimated an elevated risk of breast cancer that persists for 20 years [17], physicians may currently screen women with fibroadenomas frequently. Our study suggests that fibroadenomas do not increase risk of subsequent breast cancers. Ultimately, examining specific features of BBD will improve risk estimates used in breast cancer risk models, reduce patient anxiety, and improve management of fibroadenoma in the clinic by reducing overscreening and overtreatment of this population, both associated with potential patient harms and excessive resource allocation.

\section{Additional file}

Additional file 1: Table S1. Distribution of benign breast features and other characteristics by fibroadenoma status in women under the age of 50 years. Table S2. Distribution of benign breast features and other characteristics by fibroadenoma status for women aged 50 years or older. (DOCX $32 \mathrm{~kb}$ )

\section{Abbreviations}

BBD: Benign breast disease; FA: Fibroadenoma; HFHS: Henry Ford Health System; MDCSS: Metropolitan Detroit Cancer Surveillance System; RR: Relative risk; SEER: Surveillance, Epidemiology, and End Results program; SIR: Standardized incidence ratio; UPG: University Pathology Group

\section{Funding}

This work was supported by Susan G. Komen for the Cure (IIRG 222547 to MLC, GTDR14299438 to MLC and ANS) and the National Institutes of Health ( $\mathrm{NCl}$ grant 1F31CA22133301 to ANS).

\section{Availability of data and materials}

Please contact the authors for data requests.

\section{Authors' contributions}

MLC, DWV, SB, and RAF designed the study. EA, RS, MFD, VP, and RAF performed data acquisition. ANS and JJR had full access to all study data and take responsibility for the integrity of the data, the accuracy of the data analysis, and interpretation of data. All authors were responsible for critical revisions, and all authors read and approved the final version of this work.

\section{Ethics approval and consent to participate}

This study protocol did not involve greater than minimal risk and received expedited approval and a waiver of consent from the Wayne State University Institutional Review Board.

\section{Consent for publication}

Not applicable. No individual-level data are presented in this article.

\section{Competing interests}

The study sponsors had no role in the design of the study; the collection, analysis, or interpretation of the data; the writing of the manuscript; or the decision to submit the manuscript for publication. The authors declare they have no competing interests.

\section{Publisher's Note}

Springer Nature remains neutral with regard to jurisdictional claims in published maps and institutional affiliations.

\section{Author details}

${ }^{1}$ Department of Oncology, Wayne State University School of Medicine, 4100 John R Street, MM04EP, Detroit, MI 48201, USA. ²Department of Pathology, Wayne State University School of Medicine, Detroit, MI, USA. ${ }^{3}$ Department of Laboratory Medicine and Pathology, Mayo Clinic, Rochester, MN, USA.

${ }^{4}$ Barbara Ann Karmanos Cancer Institute, Detroit, MI, USA.

Received: 2 March 2018 Accepted: 18 July 2018

Published online: 09 August 2018

\section{References}

1. Silverstein MJ, Recht A, Lagios MD, et al. Image-detected breast cancer: state-of-the-art diagnosis and treatment. J Am Coll Surg. 2009;209(4):504-20. https://doi.org/10.1016/j.jamcollsurg.2009.07.006.

2. Dupont WD, Page DL. Risk factors for breast cancer in women with proliferative breast disease. N Engl J Med. 1985;312(3):146-51. https://doi. org/10.1056/NEJM198501173120303.

3. Hartmann LC, Sellers TA, Frost MH, et al. Benign breast disease and the risk of breast cancer. N Engl J Med. 2005;353(3):229-37. https://doi.org/10.1056/ NEJMoa044383.

4. Cote ML, Ruterbusch JJ, Alosh B, et al. Benign breast disease and the risk of subsequent breast cancer in African American women. Cancer Prev Res (Phila Pa). 2012;5(12):1375-80. https://doi.org/10.1158/1940-6207.CAPR-12-0175.

5. Gail MH, Brinton LA, Byar DP, et al. Projecting individualized probabilities of developing breast cancer for white females who are being examined annually. J Natl Cancer Inst. 1989;81(24):1879-86.

6. Kuijper A, Mommers ECM, van der Wall E, Diest V. J P. Histopathology of fibroadenoma of the breast. Am J Clin Pathol. 2001;115(5):736-42. https:// doi.org/10.1309/F523-FMJV-W886-3J38.

7. Hughes LE, Mansel RE, Webster DJT, Gravelle IH. Benign disorders and diseases of the breast: concepts and clinical management. London: Baillière Tindall; 1989.

8. Dyrstad SW, Yan Y, Fowler AM, Colditz GA. Breast cancer risk associated with benign breast disease: systematic review and meta-analysis. Breast Cancer Res Treat. 2015;149(3):569-75. https://doi.org/10.1007/s10549-014-3254-6. 
9. Oluwole SF, Freeman HP. Analysis of benign breast lesions in blacks. Am J Surg. 1979;137(6):786-9.

10. Organ $\mathrm{CH}$, Organ BC. Fibroadenoma of the female breast: a critical clinical assessment. J Natl Med Assoc. 1983;75(7):701-4.

11. DeSantis CE, Fedewa SA, Goding Sauer A, Kramer JL, Smith RA, Jemal A. Breast cancer statistics, 2015: convergence of incidence rates between black and white women. CA Cancer J Clin. 2016;66(1):31-42. https://doi.org/10. 3322/caac.21320.

12. Althuis MD, Brogan DD, Coates RJ, et al. Breast cancers among very young premenopausal women (United States). Cancer Causes Control. 2003;14(2):151-60

13. Newman LA. Breast cancer in African-American women. Oncologist. 2005; 10(1):1-14. https://doi.org/10.1634/theoncologist.10-1-1.

14. Shavers VL, Harlan LC, Stevens JL. Racial/ethnic variation in clinical presentation, treatment, and survival among breast cancer patients under age 35. Cancer. 2003;97(1):134-47. https://doi.org/10.1002/cncr.11051.

15. Earl Henson D, Chu KC, Levine PH. Histologic grade, stage, and survival in breast carcinoma. Cancer. 2003:98(5):908-17. https://doi.org/10.1002/ cncr.11558.

16. Amend K, Hicks D, Ambrosone CB. Breast cancer in African-American women: differences in tumor biology from European-American women. Cancer Res. 2006;66(17):8327-30. https://doi.org/10.1158/0008-5472.CAN06-1927.

17. Dupont WD, Page DL, Parl FF, et al. Long-term risk of breast cancer in women with fibroadenoma. N Engl J Med. 1994;331(1):10-5. https://doi.org/ 10.1056/NEJM199407073310103.

18. Nassar A, Visscher DW, Degnim AC, et al. Complex fibroadenoma and breast cancer risk: a Mayo Clinic benign breast disease cohort study. Breast Cancer Res Treat. 2015;153(2):397-405. https://doi.org/10.1007/s10549-015-3535-8.

19. Worsham MJ, Raju U, Lu M, et al. Risk factors for breast cancer from benign breast disease in a diverse population. Breast Cancer Res Treat. 2009;1 18(1): 1-7. https://doi.org/10.1007/s10549-008-0198-8.

20. Dodd GD. American Cancer Society guidelines on screening for breast cancer: an overview. CA Cancer J Clin. 1992;42(3):177-80. https://doi.org/10. 3322/canjclin.42.3.177.

21. Haus AG. Historical technical developments in mammography. Technol Cancer Res Treat. 2002;1(2):119-26.

22. Yaffe MJ, Mainprize JG, Jong RA. Technical developments in mammography. Health Phys. 2008;95(5):599-611. https://doi.org/10.1097/01.HP.0000327648. 42431.75 .

23. Greenberg R, Skornick Y, Kaplan O. Management of breast fibroadenomas. J Gen Intern Med. 1998;13(9):640-5. https://doi.org/10.1046/j.1525-1497.1998. cr188.x.

24. Sklair-Levy M, Sella T, Alweiss T, Craciun I, Libson E, Mally B. Incidence and management of complex fibroadenomas. Am J Roentgenol. 2008;190(1): 214-8. https://doi.org/10.2214/AJR.07.2330.

Ready to submit your research? Choose BMC and benefit from:

- fast, convenient online submission

- thorough peer review by experienced researchers in your field

- rapid publication on acceptance

- support for research data, including large and complex data types

- gold Open Access which fosters wider collaboration and increased citations

- maximum visibility for your research: over $100 \mathrm{M}$ website views per year

At $\mathrm{BMC}$, research is always in progress.

Learn more biomedcentral.com/submissions 